\title{
Conformational Entropy Contributions to the Glass Temperature of Blends of Miscible Polymers
}

\section{Hans Adam Schneider}

Freiburger Materialforschungszentrum, FMF, der Universität, Stefan-Mejer-Strasse 21, D-79104 Freiburg, Germany

\author{
Because of negligible contributions of com- \\ binatorial entropy, miscibility of poly- \\ mers is attributed predominantly to favor- \\ able (exothermic) enthalpic effects of \\ mixing, i.e., to strong interactions between \\ the blend components, which have to \\ overcome the cohesive forces acting within \\ the components. Miscibility of amor- \\ phous polymers usually is associated with \\ the presence of a single glass tempera- \\ ture of the blend. Although stronger hetero- \\ contact interactions are thermodynami- \\ cally required for polymer miscibility, the \\ majority of miscible binary polymer \\ blends exhibit negative deviations of the \\ glass temperature from values predicted \\ by the free volume or flexible bond additiv- \\ ity rules, suggesting a looser packing \\ within those blends. A reasonable explana- \\ tion assumes that binary hetero-contact \\ formation within the blend may be accom- \\ panied by local interchain orientation
}

contributing consequently to conformational entropy changes. The smaller the induced interchain orientation by hetero-contact formation, the larger the mobility in the neighborhood of the contacts and the probability of related conformational entropy changes, causing an equivalent increase of the "free volume" within the blend, i.e., a corresponding decrease of the blend $T_{\mathrm{g}}$, which finally can be situated below the values predicted by the additivity rules. Vice versa, the corresponding argument will hold for blends with higher interchain orientation induced by intensive exothermic hetero-contact forces.

Key words: concentration power equation; conformational entropy; flexible bond; free volume; glass transition; interchain orientation; miscible polymer blends.

Accepted: November 25, 1996

\section{Introduction}

Two major models have been proposed for the theoretical interpretation of the glass transition phenomenon characteristic of amorphous polymers. Taking into account the observed kinetic character, the free volume model considers the glass transition essentially as a freeze-in process. Nevertheless, the experimentally observed glass transition shows the characteristics of a thermodynamic second order transition, which are time dependent. The thermodynamic model assumes the existence of the glass as a thermodynamic stable fourth state of matter characterized by a real thermodynamic second order transition, but situated far below the experimentally accessible glass transition. This is supported by the "Kauzmann paradox" [1]. According to the free volume theory [2] the molecular mobility is controlled by the free volume and the glass is considered a frozen metastable state of matter, described by an additional, kinetically controlled internal order parameter [3], and a $P-V-T$ equation of state. The thermodynamic theory starts with a $S-V-T$ equation of state and the glass is supposed to be a fourth state of matter, characterized by zero conformational entropy [4]. 
Both models were used to explain the composition dependence of the glass temperature of random copolymers and blends of miscible polymers, assuming additivity of the respective basic properties of the blend components, i.e., either of the specific volumes as Gordon and Taylor have suggested [5], which is equivalent, in fact, to the additivity of the relevant free volumes, as Kovacs has demonstrated [6] or of the flexible bonds, responsible for conformational changes as DiMarzio has assumed [7].

Both additivity models result in the same GordonTaylor expression for the composition dependence of the glass temperature of the polymer blend:

$$
T_{\mathrm{g}}=\left(w_{1} T_{\mathrm{g}_{1}}+K w_{2} T_{\mathrm{g}_{2}}\right) /\left(w_{1}+K w_{2}\right)
$$

$T_{\mathrm{g}}$ is the glass temperature of the blend, whereas $w_{i}$ are the weight fractions and $T_{\mathrm{g}_{\mathrm{i}}}$ the glass temperatures of the blend components, the subscript 2 referring to the component with the higher $T_{\mathrm{g}} . K$ is a model specific parameter, i.e., $K_{\mathrm{GT}}=\left(\rho_{1} / \rho_{2}\right)\left(\Delta \alpha_{2} / \Delta \alpha_{1}\right)$ for volume additivity and $K_{\mathrm{DM}}=\left(\mu_{1} / r_{1}\right) /\left(\mu_{2} / r_{2}\right)$ for flexible bond additivity. In the latter expressions $\rho_{i}$ are the densities and $\Delta \alpha_{i}=\left(\alpha_{\text {melt }}-\alpha_{\text {glass }}\right)_{i}$ the increments at $T_{\mathrm{g}}$ of the expansion coefficients of the blend components. $\mu_{i}$ are the masses and $r_{i}$ the numbers of flexible bonds of the repeating unit.

A thermodynamic approach to the compositional dependence of the glass temperature of compatible polymer blends has also been suggested by Couchman and Karasz [8]. The approach is based on the supposition of continuity of the thermodynamic excess functions at $T_{\mathrm{g}}$ and equality of the respective excess functions of mixing of the melt and glass. The problem of this approach is, however, that for volume and enthalpy a linear GordonTaylor like expression results, whereas for entropy a logarithmic Gordon-Taylor like expression is obtained. In the respective linear equation for compositional dependence of the blend $T_{\mathrm{g}}$ based on the enthalpy approach and the logarithmic equation based on the entropy approach the value, of the $K$ parameter is related to the ratio of the increments of the heat capacities of the blend components, $K_{\mathrm{CK}}=\left(\Delta C_{p 2} / \Delta C_{p 1}\right)$. According to Boyer's rule, $\Delta C_{p} T_{\mathrm{g}}=$ constant [9] the $K$ parameter can be substituted in the respective Gordon-Taylor like equations by $K_{\mathrm{CK}}=T_{\mathrm{g}_{1}} / T_{\mathrm{g}_{2}}$. The problem is, however, that an entropy based logarithmic and an enthalpy based linear Gordon-Taylor like equation are not compatible when applied for the same blend.

Assuming the validity of the Simha-Boyer rule, [10], $\Delta \alpha T_{\mathrm{g}}=0.133$ (constant), and neglecting in a first approximation the influence of the mostly very similar densities of the blend components, i.e., considering $\left(\rho_{1} / \rho_{2}\right) \approx 1$, the specific $K_{\mathrm{GT}}$ parameter for volume addi- tivity can also be substituted by the respective reversed ratio of the glass temperatures of the blend components, $K_{\mathrm{GT}} \approx T_{\mathrm{g}_{1}} / T_{\mathrm{g}_{2}}$. Introducing this value for $K$ in the Gordon-Taylor equation [Eq. (1)] the well known Fox equation results [11].

$$
1 / T_{\mathrm{g}}=w_{1} / T_{\mathrm{g}_{1}}+w_{2} / T_{\mathrm{g}_{2}} .
$$

Although originally proposed for copolymers, the Fox equation can be considered to be valid in a first rough approximation for supposed additivity of the volume, i.e., of the free-volume of the blend components.

Surprisingly, both models, i.e., the Fox equation [Eq. (2)] for assumed volume additivity and the DiMarzio equation, i.e., Eq. (1) with $K_{\mathrm{DM}}=(\mu / r)_{1} /(\mu / r)_{2}$ expressed for flexible bond additivity, predict the same composition dependence of the glass temperature of compatible polymer blends as shown by Schneider and DiMarzio [12]. But these additivity-rules- based equations are not able to describe either the experimentally observed positive or negative deviations of the blend $T_{\mathrm{g}}$ from the predicted additivity values $[12,13]$. The fact that both models predict the same composition dependence of the blend $T_{\mathrm{g}}$ is supported by direct correlation between the ratios of the glass temperatures, $T_{\mathrm{g}_{1}} / T_{\mathrm{g}_{2}}$, and of the masses/flexible bonds of the monomeric units of the blend components, $(\mu / r)_{1} /(\mu / r)_{2}$, shown in Fig. 1. Accordingly, it was supposed by Schneider and DiMarzio [13] that the glass temperature of polymers can be related in a first approximation to the mass/flexible bond of the monomeric unit.

In Fig. 1 are emphasized some of the queries related either with the fact that the influence of possibly very different densities of the polymers is neglected (exemplified for the blend poly(vinilydene floride)/poly(methyl methacrylate) - $\mathrm{PVF}_{2} / \mathrm{PMMA}$ ) or with difficulties encountered in an exact evaluation of the number of flexible bonds of the repeating unit. Thus for instance in poly(styrene), PS, the bond between the planar phenyl ring and backbone can be considered either flexible or not, depending if one assumes or not that two different conformations result depending if the phenyl ring is in plane or out of plane with the backbone. Accordingly two different values for $(\mu / r)_{\mathrm{PS}}$ may be used. This is illustrated in Fig. 1 for the blends PS/PPO - (poly(2,3-dimethyl-1,4-phenylene ether), PS/PC - tetramethyl bisphenol-A polycarbonate, and $\mathrm{PS} / \mathrm{P} \alpha \mathrm{MS}$ poly ( $\alpha$-methyl styrene). Additionally intramolecular or intermolecular interactions may contribute to a stiffening of flexible single bonds or loosening of double bonds. This is exemplified for the probable free electron - $\pi$ electron interaction in the acceptor polyacrylates or -methacrylates of ( $\beta$-hydroxyethyl-3,5-dinitrobenzoyl) blended with donor poly-acrylates or -methacrylates of 


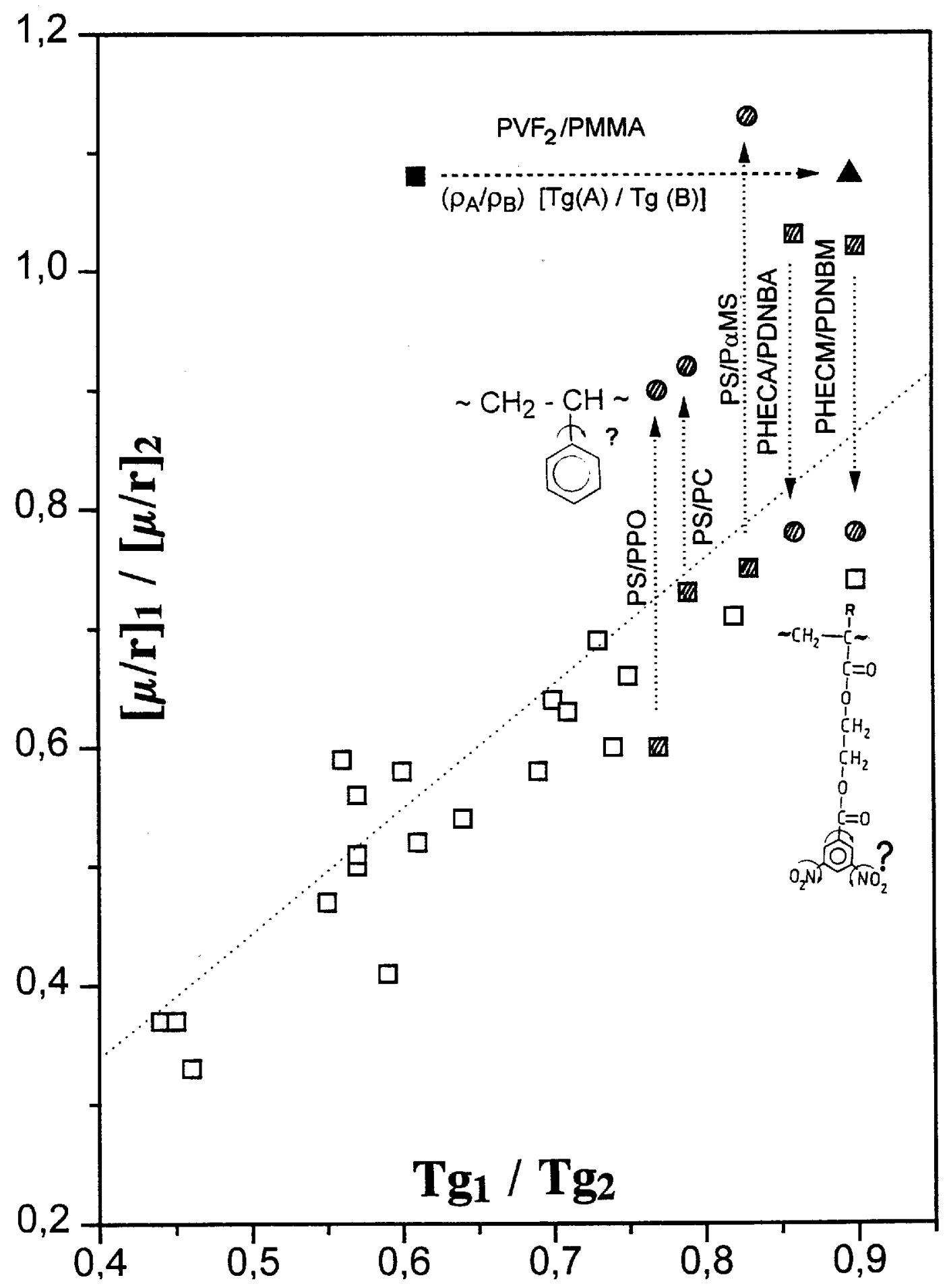

Fig. 1. Ratio of the masses/'flexible' bonds, $[\mu / r]_{1} /[\mu / r]_{2}$ vs ratio of the glass temperatures $T_{\mathrm{g}_{1}} / T_{\mathrm{g}_{2}}$ of the components of compatible blends.

N(2-hydroxy-ethyl)carbazolyl, i.e. DNBA/PHECA and DNBM/PHECM, respectively. Due to the free electron - $\pi$ electron interaction the bonds of the dinitrobenzoylgroup, indicated by arrows, can be considered either stiffened or not. A corresponding shift of the values of the $(\mu / r)$-ratio along the dotted lines would be the consequence. 
These uncertainties concerning an unambiguous determination of the number of flexible bonds of the repeating unit because of possible interactions could be one of the explanations for the observed relatively large scatter of $T_{\mathrm{g}}$ vs mass/flexible bond of monomeric unit data shown in Fig. 10 of the paper published by Schneider and DiMarzio [13]. Nevertheless, the scatter of the data is not larger than for the correlation between $T_{\mathrm{g}}$ and conformational flexibility and mass moments of the polymer, recommended by Hopfinger et al. for prediction of polymer glass transition temperature [14]. The assumption that the scatter of the respective $T_{\mathrm{g}}$ vs mass/flexible bond data is related principally with uncertainties in an exact evaluation of the number of flexible bonds is supported by the observation that the $T_{\mathrm{g}} \mathrm{vs}$ mass/flexible bond rule holds exactly for different classes of polymers as it results from the data illustrated in Fig. 2. Besides literature data for polyolefins, poly(acrylate)s and -(methacrylate)s as well for poly(N-alkylacrylamide)s and for poly(4-alkylstyrene)s [15], are presented our own data for aromatic main chain polymers bearing an increasing number of flexible segments between the aromatic units, i.e., poly(amide imide)s, poly(aramide)s [16] and poly(etherketone)s [17], as well for the polyacceptors, PDNBM, and polydonors, PHalkylCM, containing in the methacrylic side chain an increasing number of methylenes between the methacrylic and the respective electron interacting group [18].

\section{Concentration Power Equations for the Composition Dependence of the Blend $T_{\mathrm{g}}$}

To account for the effect on $T_{\mathrm{g}}$ of interactions in polymer blends, empirical concentration second power equations have been proposed in the literature. Jenckel and Heusch [19], for instance, suggested for plasticized polymer blends the expression:

$$
T_{\mathrm{g}}=w_{1} T_{\mathrm{g}_{1}}+w_{2} T_{\mathrm{g}_{2}}+b\left(T_{\mathrm{g}_{2}}-T_{\mathrm{g}_{1}}\right) w_{1} w_{2}
$$

with $b$ a parameter which characterizes the solvent quality of the plasticizer. Kwei [20], for his part, extended the Gordon-Taylor equation, introducing in Eq. (1) an additional square concentration term, $q w_{1} w_{2}, q$ being considered an interaction dependent parameter. Additionally, the $K$ parameter is treated as a real fitting parameter of the resulting concentration second power equation:

$$
T_{\mathrm{g}}=\left(w_{1} T_{\mathrm{g}_{1}}+K w_{2} T_{\mathrm{g}_{2}}\right) /\left(w_{1}+K w_{2}\right)+q w_{1} w_{2}
$$

Concentration second power equations for the compositional dependence of the blend $T_{\mathrm{g}}$ were also obtained by DiMarzio [7], by assuming beside flexible bond additivity, the effect of volume changes due to the different specific volumes of the blend components at $T_{\mathrm{g}}$ and by Kanig [21], who related the changes in interaction energies to the respective Gibbs energies for generating one mole of holes in the equilibrium polymer melt.

Brekner et al. [22] have suggested that the glass transition temperature of compatible polymer blends depends on the free volume distribution and the related conformational mobility, which is controlled by the probability of hetero-molecular contact formation in the mixture due to specific interactions of the components. Applying the lattice theory of regular solutions and supposing that the number of each contact type, both homoand hetero-contacts, is related with the respective volume fraction of the components, the following concentration second power equation was obtained:

$$
\left(T_{\mathrm{g}}-T_{\mathrm{g}_{1}}\right) /\left(T_{\mathrm{g}_{2}}-T_{\mathrm{g}_{1}}\right)=\left(1+K_{1}\right) \phi-K_{1} \phi^{2}
$$

with $\phi$ the volume fraction of the component with the higher $T_{\mathrm{g}}$. The $K_{1}$ parameter is given by the expression $K_{1}=\left(2 E_{12}-\left(E_{11}+E_{22}\right) /\left(T_{\mathrm{g}_{2}}-T_{\mathrm{g}_{1}}\right), E_{i j}\right.$ being the respective contact-specific interaction enthalpy. Additivity is thus characterized by $K_{1}=0$, i.e., the contribution of the intermolecular-hetero contacts is identical with the mean of the binary-homo contacts. The resulting expression for additivity

$$
\left(T_{\mathrm{g}}-T_{\mathrm{g}_{1}}\right) /\left(T_{\mathrm{g}_{2}}-T_{\mathrm{g}_{1}}\right)=\phi
$$

is identical to the Gordon-Taylor equation [Eq. (1)] rearranged in the form:

$$
\left(T_{\mathrm{g}}-T_{\mathrm{g}_{1}}\right) /\left(T_{\mathrm{g}_{2}}-T_{\mathrm{g}_{1}}\right)=K_{\mathrm{GT}} w_{2} /\left(w_{1}+K_{\mathrm{GT}} w_{2}\right)=w_{2 \mathrm{c}}
$$

i.e., the volume fraction, $\phi$, of the component with the higher $T_{\mathrm{g}}$ is identical with the weight fraction, $w_{2 \mathrm{c}}$, corrected to account for the differences in density and expansivity of the blend components. Accordingly, Eq. (5) can be expressed as follows:

$$
\left(T_{\mathrm{g}}-T_{\mathrm{g}_{1}}\right) /\left(T_{\mathrm{g}_{2}}-T_{\mathrm{g}_{1}}\right)=\left(1+K_{1}\right) w_{2 \mathrm{c}}-K_{1} w_{2 \mathrm{c}}{ }^{2} .
$$

Taking into account the thermodynamic condition of miscibility, $\Delta G_{\mathrm{m}}=\Delta H_{\mathrm{m}}-T \Delta S_{\mathrm{m}}<0$, and that for polymers the combinatorial entropy of mixing is negligible, i.e., $\Delta S_{\mathrm{m}} \sim 0$, the enthalpy of mixing has to be exothermic to assure polymer miscibility, i.e., $\Delta H_{\mathrm{m}}<0$. That means the energy of hetero-contact interaction has to overcome the energies of homo-contact interactions, i.e., 


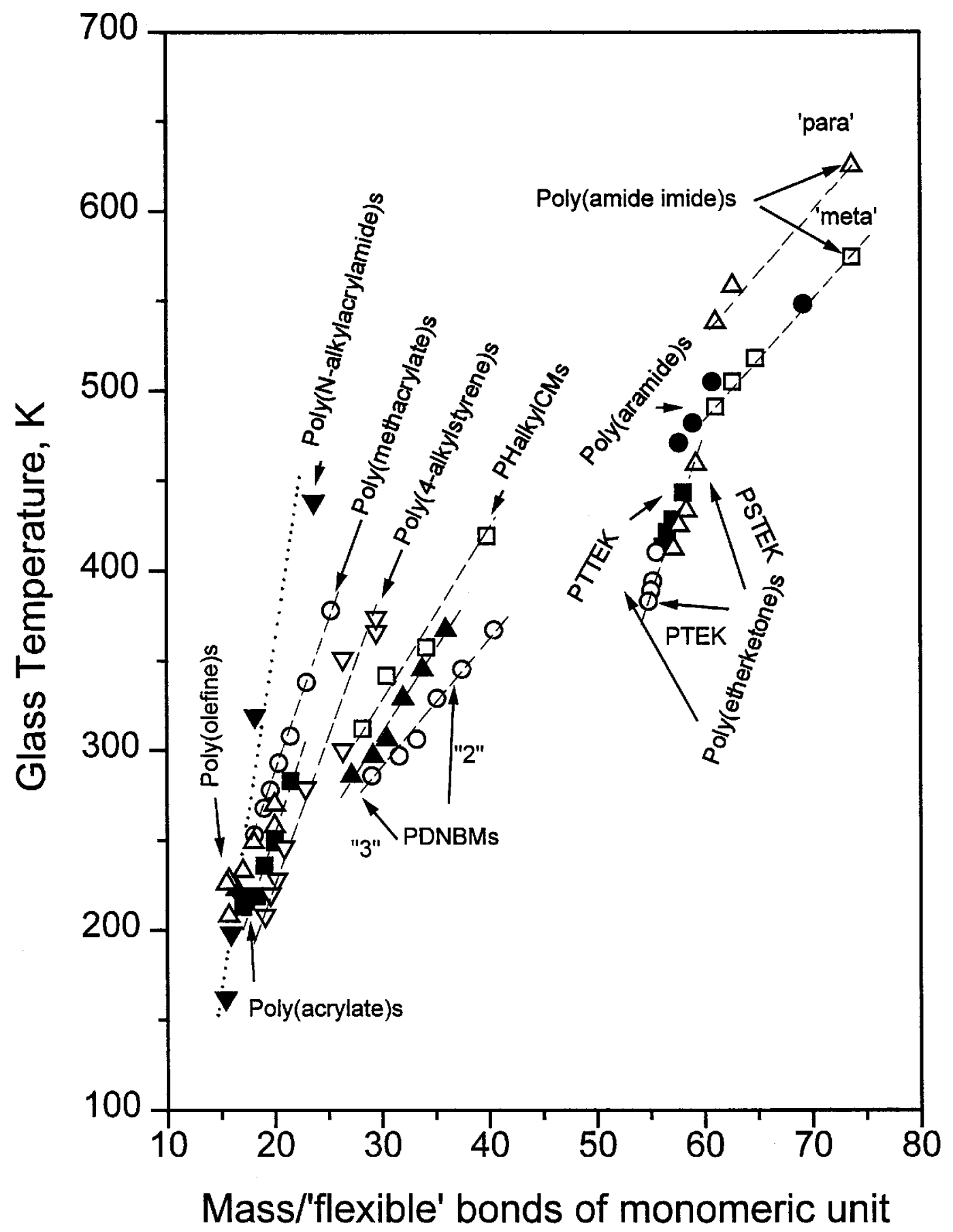

Fig. 2. Glass temperature vs mass/'flexible' bond of the monomeric unit for different classes of polymers.

always $E_{12}>1 / 2\left(E_{11}+E_{22}\right)$, for $K_{1}>0$ in Eq. (8). Thus considering the effect of interactions only, by Eq. (8) exclusive positive deviations from additivity of the blend $T_{\mathrm{g}}$ can be explained, taking into account that $K_{1} w_{2 \mathrm{c}}>$ $K_{1} w_{2 \mathrm{c}}{ }^{2}$ for any weight fraction.

To explain negative deviations from additivity the binary contact model was extended to account for the effect of the hetero-contact formation on conformational rearrangements in the immediate molecular neighborhood of the binary contacts, accompanied by corresponding conformational entropy changes, see Refs. [22] and [23]. The result is a virial-like concentration third power equation: 


$$
\begin{aligned}
\left(T_{\mathrm{g}}-T_{\mathrm{g}_{1}}\right) /\left(T_{\mathrm{g}_{2}}-T_{\mathrm{g}_{1}}\right) & =\left(1+K_{1}\right) w_{2 \mathrm{c}}-\left(K_{1}+K_{2}\right) w_{2 \mathrm{c}}{ }^{2} \\
+ & K_{2} w_{2 \mathrm{c}}^{3}
\end{aligned}
$$

where the parameters are expressed by:

$$
K_{1}=\left\{\left[\left(E_{12-1}+E_{12-2}\right)-\left(E_{11-1}+E_{22-2}\right)\right]\right.
$$

energetic interactions, always $>0$

$$
\left.-\left[\left(e_{12-2}-e_{12-1}\right)+\left(e_{11-1}-e_{11-2}\right)\right]\right\} /\left(T_{\mathrm{g}_{2}}-T_{\mathrm{g}_{1}}\right)
$$

effects induced by conformational changes

$$
\begin{gathered}
K_{2}=\left\{\left[\left(2 e_{12-1}-\left(e_{11-12}+e_{22-1}\right)\right]\right.\right. \\
-\left[2 e_{12-2}-\left(e_{22-2}+e_{22-1}\right)\right] /\left(T_{\mathrm{g}_{2}}-T_{\mathrm{g}_{1}}\right) . \\
\Downarrow
\end{gathered}
$$

energetic effects induced by conformational changes

$K_{1}$ depends essentially on the difference between the interaction energies of hetero- and homo-contacts, but it includes also the effects of the induced conformational changes in the neighborhood by hetero-contact formation. $E_{11-1}=E_{11}+e_{11}$ and $E_{22-2}=E_{22}+e_{22}$, respectively, characterize the behavior of the pure components, whereas the hetero-contact formation is considered either in an exclusive environment of component 1 or 2 , i.e., $E_{12-1}=E_{12}+e_{12-1}$ or $E_{12-2}=E_{12}+e_{12-2}$. The first rectangular bracket of $K_{1}$ accounts consequently for the energetic effects resulting from the substitution of one homo-contact by a hetero-contact in the pure homo-environment. The second rectangular bracket of the parameter $K_{1}$ includes by the first difference $\left(e_{12-1}-\right.$ $e_{12-2}$ ) the conformational determined effects of substitution in the surroundings of the binary hetero-contact of one neighbor 1 by a neighbor 2 . The second difference $\left(e_{11-2}-e_{11-1}\right)$ is the consequence of the asymmetry of the concentration power Eq. (9) because of choosing as the effective variable the volume fraction, i.e., the corrected weight fraction, $w_{2 c}$, of the stiffer component with the higher $T_{\mathrm{g}}$. This asymmetry is reflected in the difference between the parameters $K_{1}$ and $K_{2}$.

$$
\begin{array}{r}
K_{1}-K_{2}=\left\{\left[\left(E_{12-1}+E_{12-2}\right)-\left(E_{11-1}+E_{22-2}\right)\right]\right. \\
\left.-\left[\left(e_{12-1}-e_{12-2}\right)+\left(e_{22-2}-e_{22-1}\right)\right]\right\} /\left(T_{\mathrm{g}_{2}}-T_{\mathrm{g}_{1}}\right) .
\end{array}
$$

Comparing Eq. (12) with Eq. (10) for $K_{1}$ shows that they differ exclusively by the contributions of conformational changes, comprised in the respective second rectangular brackets. In the first difference term included in the brackets in fact only the order of the conformational influences of the homo-environments on hetero-contacts is inversed. The second differences corroborate effectively the asymmetry of the respective expressions. Thus in Eq. (10) the influence of substitution of one component 1 by component 2 in the pure environment of component 1 is considered, whereas in Eq. (12) the opposite substitution is taken into account.

In Eq. (11) for the parameter $K_{2}$ the first difference represents the effects induced by the conformational changes due to hetero-contact formation in a predominately component 1 , whereas the second difference refers to the same effect of hetero-contact formation in the predominantly component 2 environment. The parameter $K_{2}$ can thus be assumed to be characteristic for energetic influences on the binary contact interaction due to entropy changes induced by the conformational rearrangements caused by hetero-contact formation in the binary compatible polymer blend.

Unfortunately, the parameters $K_{1}$ and $K_{2}$ are not yet accessible by other means but only via fitting of the concentration third power Eq. (9) to experimental $T_{\mathrm{g}}$ vs concentration data of compatible polymer blends. Thus, it is not possible to separate the compositional dependent enthalpic from the conformational induced entropic contributions to the glass temperature of polymer blends. Nevertheless, by using the concentration power Eq. (9), it is possible to explain additionally the observed negative deviations from additivity of the blend $T_{\mathrm{g}}$, because depending on the conformational entropy contributions, both the parameters $K_{1}$ and $K_{2}$ can adapt not only positive, but also negative values.

\section{Results and Discussions}

In Table 1 are presented the values of the fitting parameters of the virial-like concentration power Eq. (9) for the compositional dependence of the glass temperature of some representative compatible blends of homopolymers. For the evaluation of the fitting parameters both literature and our own $T_{\mathrm{g}}$ vs composition data of binary polymer blends were used. The blends are arranged in Table 1 according to decreasing values of the $K_{1}$ parameter. Taking into account the values of $K_{1}$ and of the difference of the $\left(K_{1}-K_{2}\right)$ parameters, the blends can be arranged into five major classes which show different specific $T_{\mathrm{g}}$ vs composition curves.

In the first class are included the blends characterized by positive values of both $K_{1}$ and the $\left(K_{1}-K_{2}\right)$ difference. Depending on the values of the parameters the blends show all more or less pronounced positive deviations from additivity of the blend $T_{\mathrm{g}}$ as it results from the data presented in Fig. 3. Beside the curves fitted according to the virial like concentration power Eq. (9) are shown both the curves predicted by the volume (Foxdotted lines) and by the mass/flexible bond additivity 
Table 1. Parameters of the concentration power equation applied to the glass temperature of compatible polymer blends

$$
\begin{gathered}
\left(T_{\mathrm{g}}-T_{\mathrm{g}_{1}}\right) /\left(T_{\mathrm{g}_{2}}-T_{\mathrm{g}_{1}}\right)=\left(1+K_{1}\right) w_{2 \mathrm{c}}-\left(K_{1}+K_{2}\right) w_{2 \mathrm{c}}{ }^{2}+K_{2} w_{2 \mathrm{c}}{ }^{3} \\
w_{2 \mathrm{c}}=K w_{2} /\left(w_{1}+K w_{2}\right) ; K=T_{\mathrm{g}_{1}} / T_{\mathrm{g}_{2}}
\end{gathered}
$$

\begin{tabular}{lllllll}
\hline \hline Blend & $K=T_{\mathrm{g}_{1}} / T_{\mathrm{g}_{2}}$ & $K_{1}$ & $K_{2}$ & $K_{1}-K_{2}$ & Ref. \\
\hline
\end{tabular}

Blend $T_{\mathrm{g}}$-positive deviations from additivity; $\Delta T_{\mathrm{g}}>0$

characteristic of prevailing enthalpic effects due to strong interactions

$K_{1}$ and $K_{1}-K_{2}>0$; see Fig. 3

\begin{tabular}{|c|c|c|c|c|c|}
\hline \multicolumn{6}{|c|}{$\begin{array}{c}\text { S-shaped } T_{\mathrm{g}} \text { vs composition curves } \\
K_{1}>0 \text { and } K_{1}-K_{2}<0 \text {; see Fig. } 4\end{array}$} \\
\hline $\mathrm{P}$ (butylene adipate)/P(epichlorohydrine) & 0.82 & 0.32 & 1.45 & -1.13 & [28] \\
\hline $\mathrm{PS} / \mathrm{PC}$ & 0.79 & 0.22 & 1.89 & -1.67 & {$[29],[30]$} \\
\hline \multicolumn{6}{|c|}{$\begin{array}{l}\text { Blend } T_{\mathrm{g}}-\text { almost additive; } \Delta T_{\mathrm{g}} \sim 0 \\
\quad\left|K_{1}\right| \text { and }\left|K_{2}\right|<0.5 \text {; see Fig. } 5\end{array}$} \\
\hline $\mathrm{P}($ ethylene oxide)/PMMA & 0.56 & 0.22 & 0.36 & -0.14 & [31] \\
\hline $\mathrm{P}(\epsilon$-caprolactone $) / \mathrm{PVC}$ & 0.57 & 0.04 & 0.37 & -0.33 & [32] \\
\hline PS/P(2,6-dimethylphenylene oxide) & 0.77 & -0.08 & 0.11 & -0.19 & [33] \\
\hline \multicolumn{6}{|c|}{$\begin{array}{c}\text { S-shaped } T_{\mathrm{g}} \text { vs composition curves } \\
K_{1}<0 \text { and } K_{1}-K_{2}>0 \text {; see Fig. } 6\end{array}$} \\
\hline $\mathrm{P}(\alpha$-methylstyrene $) / \mathrm{PC}$ & 0.73 & -0.42 & -1.49 & 1.07 & [29] \\
\hline $\mathrm{P}(\epsilon$-caprolactone $) / \mathrm{PC}$ & 0.44 & -0.84 & -1.72 & 0.88 & {$[34],[35]$} \\
\hline $\mathrm{P}$ (butylene sebacate)/PC & 0.45 & -1.21 & -2.24 & 1.03 & [34] \\
\hline
\end{tabular}

\begin{tabular}{llllll}
\hline PDNBM/PHECM & 0.90 & 2.42 & 1.90 & 0.52 & {$[24]$} \\
PDNBA/PHECA & 0.86 & 1.12 & 0.51 & 0.61 & {$[25]$} \\
P(vinylidene flouride)/PMMA & 0.61 & 1.42 & 0.84 & 0.58 & {$[26]$} \\
ULTEM $^{\mathrm{R}} /$ P(Benzimideazole) & 0.70 & 0.95 & -0.19 & 1.14 & {$[27]$} \\
\hline
\end{tabular}

Blend $T_{\mathrm{g}}$-negative deviations from additivity; $\Delta T_{\mathrm{g}}<0$

characteristic of prevailing confromational entropic effects for weaker interactions $K_{1}$ and $K_{1}-K_{2}<0$; see Fig. 7

\begin{tabular}{llrrrl}
\hline Pdimethpropsucc/PHEBA & 0.69 & -0.91 & 0.02 & -0.93 & {$[36]$} \\
$\mathrm{P}($ vinylmethyl ether)/PS & 0.65 & -1.28 & -0.99 & -0.29 & {$[37],[38]$} \\
PS/P $\alpha$ MS & 0.83 & -2.40 & -2.05 & -0.35 & {$[39]$}
\end{tabular}

PDNBM resp. PDNBA - poly( $\omega$-hydroxyethyl-3,5-dinitrobenzoyl methacrylate) resp. -acrylate)

PHECM resp. PHECA - poly[N-(2-hydroxyethyl)carbazolyl methacrylate) resp. -acrylate)

$\mathrm{ULTEM}^{\mathrm{R}}$ - poly $\left\{\left[2,2^{\prime}\right.\right.$-bis(3,4-dicarboxyphenoxy)phenylpropane]-2-phenylene-bisimide $\}$

PC - tetramethyl-bisphenol-A-polycarbonate; PHEBA - polyhydroxyether of bisphenol-A

$\mathrm{P}$ (dimethpropsucc) - poly(2,2'dimethyl-1,3-propylene succinate).

model (DiMarzio-dashed lines). Except for $\mathrm{PVF}_{2} /$ PMMA, in Fig. 3 the same $T_{\mathrm{g}}$ behavior is predicted by both additivity models for the three other blends shown. In fact, of all studied polymer blends, the $\mathrm{PVF}_{2} / \mathrm{PMMA}$ blend is the only one which shows different behavior for volume and mass/flexible bond additivity. But taking into account the very different densities of the two homopolymers, a corrected Fox-volume additivity model (see thick dotted line) predicts almost the same behaviour as the mass/flexible bond model.

Values of the $K_{2}$ parameter very different from zero are characteristic for asymmetric $T_{\mathrm{g}}$ vs blend composi- tion curves. For absolute values of $\left|K_{2}\right|>\left|K_{1}\right|$, the difference of the fitting parameters, $\left(K_{1}-K_{2}\right)$, has always the opposite sign from $K_{1}$ and the corresponding $T_{\mathrm{g}}$ vs blend composition curves are $\mathrm{S}$-shaped.

For the pair $K_{1}>0$ and $\left(K_{1}-K_{2}\right)<0$, the respective $T_{\mathrm{g}}$ vs composition curves show generally positive deviations from additivity for higher concentrations of component 1 with the lower $T_{\mathrm{g}_{1}}$ and negative deviations in the high concentration range of the component 2 with the higher $T_{\mathrm{g}_{2}}$. This is illustrated in Fig. 4 for the blends PS/PC and poly(butylene adipate)/poly(epichlorohydrine) - PBuAdip/PepiClHyd -, respectively. The larger 


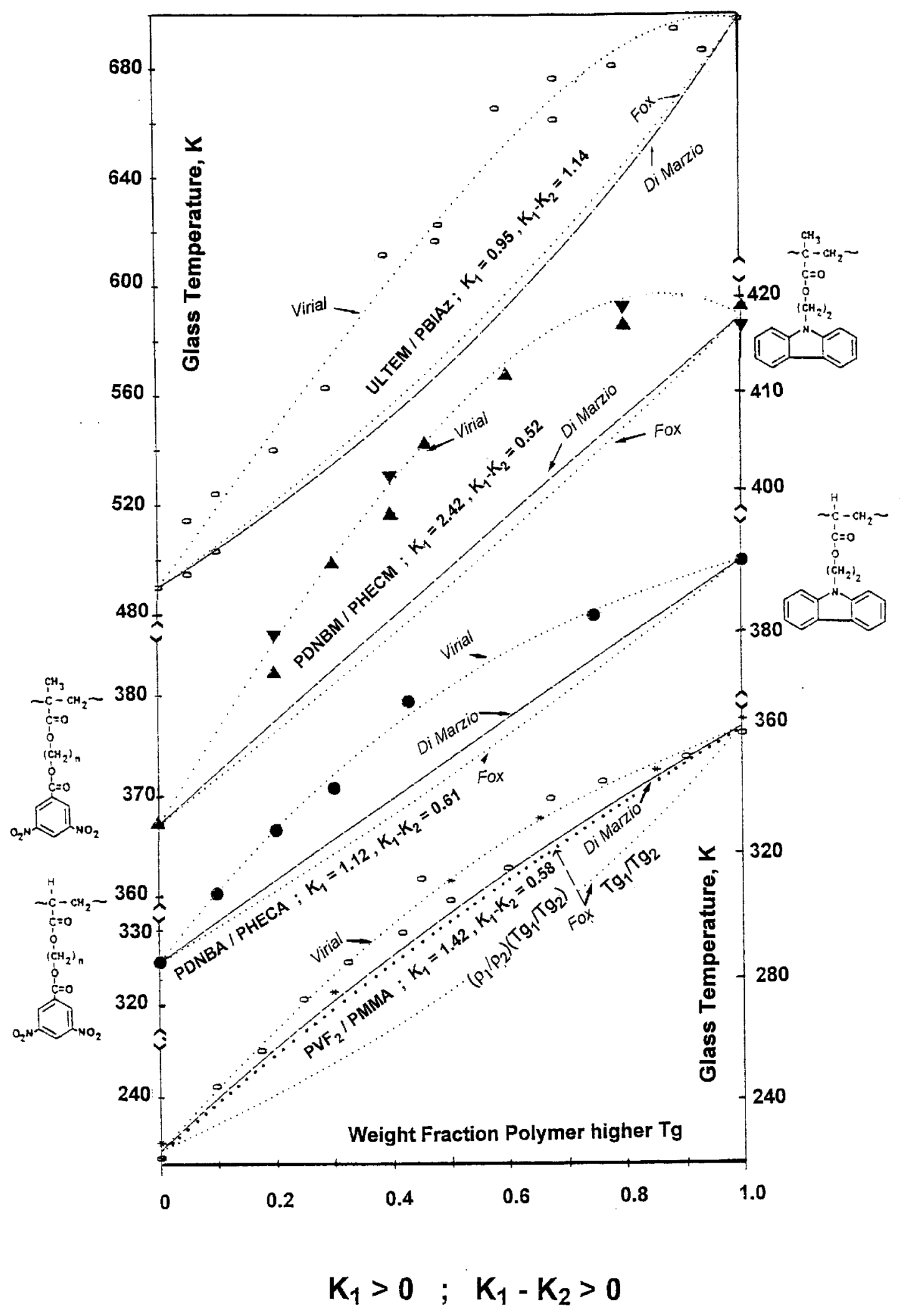

Fig. 3. $T_{\mathrm{g}}$ vs weight fraction of the polymer blend component with the higher $T_{\mathrm{g}_{1}}$ for polymer blends with positive deviations of the $T_{\mathrm{g}}$ from additivity. 


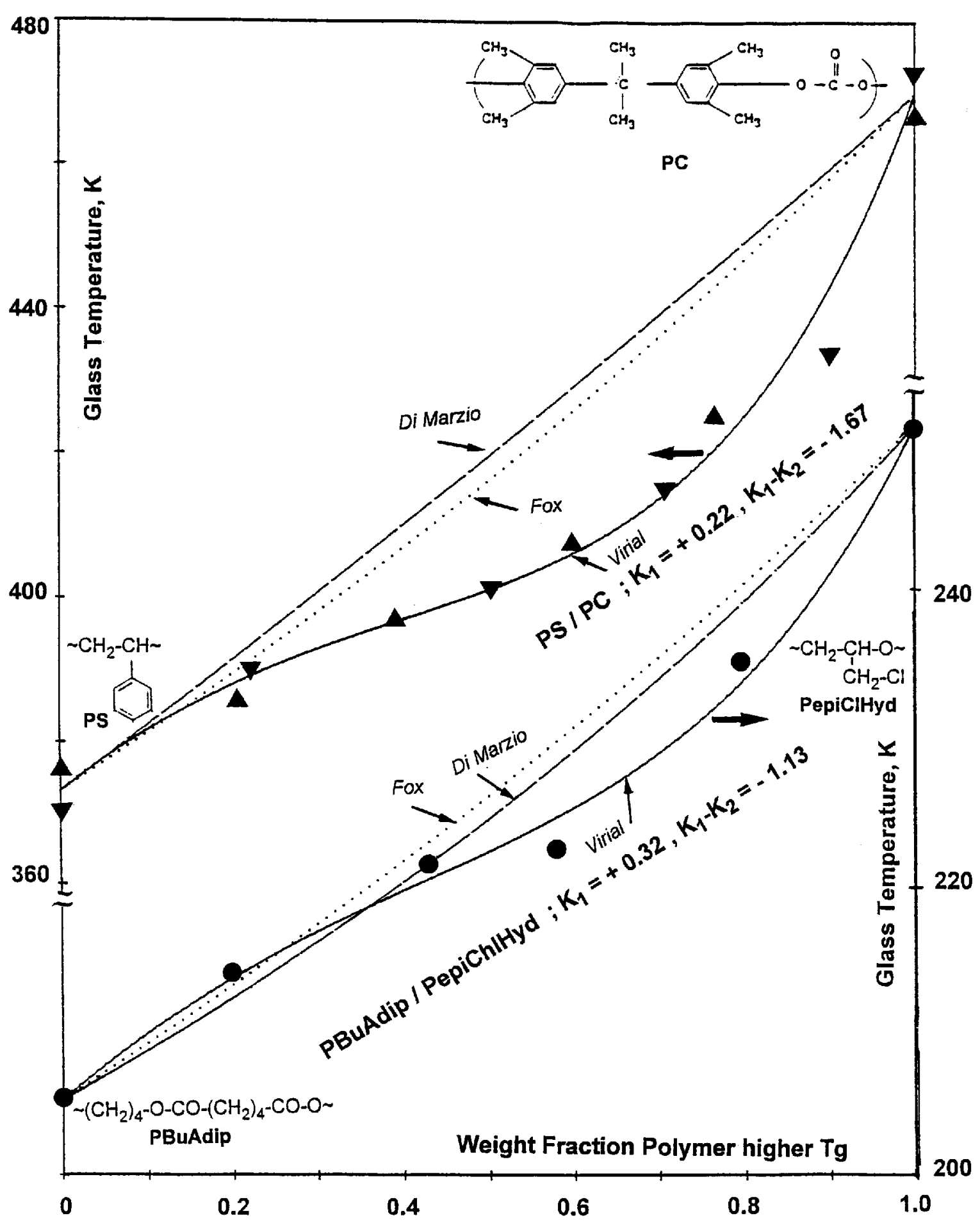

\section{$\mathrm{K}_{1}>0 ; \mathrm{K}_{1}-\mathrm{K}_{2}<0$}

Fig. 4. S-shaped $T_{\mathrm{g}}$ vs composition curves for polymer blends characterized by the parameters of the concentration power equation $K_{1}>0 ;\left(K_{1}-K_{2}\right)<0$. 
the difference between the positive $K_{1}$ and the negative $\left(K_{1}-K_{2}\right)$ values, the larger the negative deviations from additivity of the blend $T_{\mathrm{g}}$ in the high concentration range of the component 2 with the higher $T_{\mathrm{g}_{2}}$.

Additivity of the blend $T_{\mathrm{g}}$ is observed for values of the two fitting parameters, $K_{1}$ and $K_{2}$, of the concentration power equation ranged between +0.4 and -0.4 . In this case the compositional dependence of the glass temperature is predicted by both the volume additivity (Fox) and flexible bond additivity (DiMarzio) models. This is demonstrated in Fig. 5 for the blends: PS/PPO, poly(ethylene oxide)/poly(methyl methacrylate) - PEO/ PMMA - and poly( $\epsilon$-caprolactone $) /$ poly(vinyl-chloride) - P€CL/PVC.

Taking into account that for volume additivity the $K$ parameter of the Gordon-Taylor equation can be substituted in a first approximation by $T_{\mathrm{g}_{1}} / T_{\mathrm{g}_{2}}$, the $T_{\mathrm{g}}$ vs composition curves are always slightly concave.

The form of the S-shaped blend $T_{\mathrm{g}}$ vs composition curves is reversed if $K_{1}<0$ and $\left(K_{1}-K_{2}\right)>0$ i.e., they show negative deviations in the high concentration range of the component 1 with the lower $T_{\mathrm{g}_{1}}$ and positive deviations in the high concentration range of the component 2 with the higher $T_{\mathrm{g}_{2}}$. This is illustrated in Fig. 6 for the blends of PC with P $\alpha \mathrm{MS}$, poly(butylene sebacate) PBuSeb - and poly( $\epsilon$-caprolactone).

Finally, negative deviations of additivity are characterized by negative values of both the $K_{1}$ parameter and the difference, $\left(K_{1}-K_{2}\right)$, between the fitting parameters of the concentration power equation-see Fig. 7. Again the two additivity models predict the same behavior and are not able to describe experimental $T_{\mathrm{g}}$ vs composition data.

Considering the nature of the interaction energies needed to assure compatibility of polymers it may be assumed that the stronger the interaction energy, the larger the probability of an induced neighboring heterocontact formation accompanied by a local interchain ordering, restricting the conformational mobility in the neighborhood of the hetero-contacts. As a consequence, both the conformational entropy and the free volume are diminished in the blend. This is reflected by an increase of the blend glass temperature above the temperature predicted by additivity rules. Accordingly, polymer blends characterized by strong interactions will show positive deviations from additivity of the blend glass temperature, like the PDNBM/PHECM blend bearing strong electron donor-electron acceptor interaction. Blends with weaker interaction energies, as for instance the $\pi-\pi$ electron interaction in the PS/P $\alpha$ MS blend, will show less or no local ordering due to hetero-contact formation and thus an enhanced conformational mobility. Accordingly both conformational entropy and free volume will increase, whereas the blend $T_{\mathrm{g}}$ shows nega- tive deviations from additivity. These possible opposite effects of local ordering by hetero-contact formation are sketched in Fig. 8.

The assumed local ordering effect of hetero-contact interaction is supported by the data presented in Fig. 9. For the strong electron donor-electron acceptor interaction the probability of neighboring hetero-contact formation by charge transfer complexation of the acceptor poly( $\beta$-hydroxyalkyl-3,5-dinitrobenzoyl methacrylate) with the donor poly-[N(2-hydroxy-ethyl)carbazoyl methacrylate] is additionally enhanced by the increasing spacer length between the interacting dinitrobenzoyl electron acceptor group and the methacrylic backbone as it results from Fig. 9 using data published in [18]. For weaker interactions, on the contrary, the probability of hetero-contact formation is decisively influenced by the molecular weight of the blend components. The higher the molecular weight, the more probable the coiling of the polymers and thus the less accessible are the interacting groups for a random hetero-contact formation. Accordingly, the negative deviation of the blend $T_{\mathrm{g}}$ from additivity will decrease with increasing molecular weight of the blend components. This is illustrated in Fig. 9 for PVME/PS blends, using data published by Schneider and Leikauf [38].

It may thus be supposed that the weaker the interaction energy between the blend components, the less probable the local ordering effect of hetero-contact formation on the immediate environment allowing additional conformational rearrangements. As a consequence, the conformational entropy contribution to the polymer miscibility increases. These prevailing conformational entropy effects will contribute to an increase of the free volume and a corresponding decrease of the blend $T_{\mathrm{g}}$. Predominant energetic interaction effects, on the contrary, will cause an increase of the glass transition due to the denser packing in the blend because of decreasing mobility and free volume conditioned by the local ordering effect of hetero-contact formation. It may thus be assumed that additivity in polymer blends is the consequence of compensation of energetic interaction effects and conformational entropy contributions to polymer miscibility. The situation concerning the balance between conformational entropy and enthalpy contributions and its influence on the glass temperature of miscible polymer blends is analogous to the $\theta$-point situation in polymer solutions, where the balance of enthalpic and entropic contributions depends on the strength of the specific polymer-solvent interaction.

Taking into account that enthalpy of mixing of polymers is connected in a first approximation to the mutual solubility of the components, subsequently it is attempted to correlate the fitting parameters of the concentration power equation with the difference between 


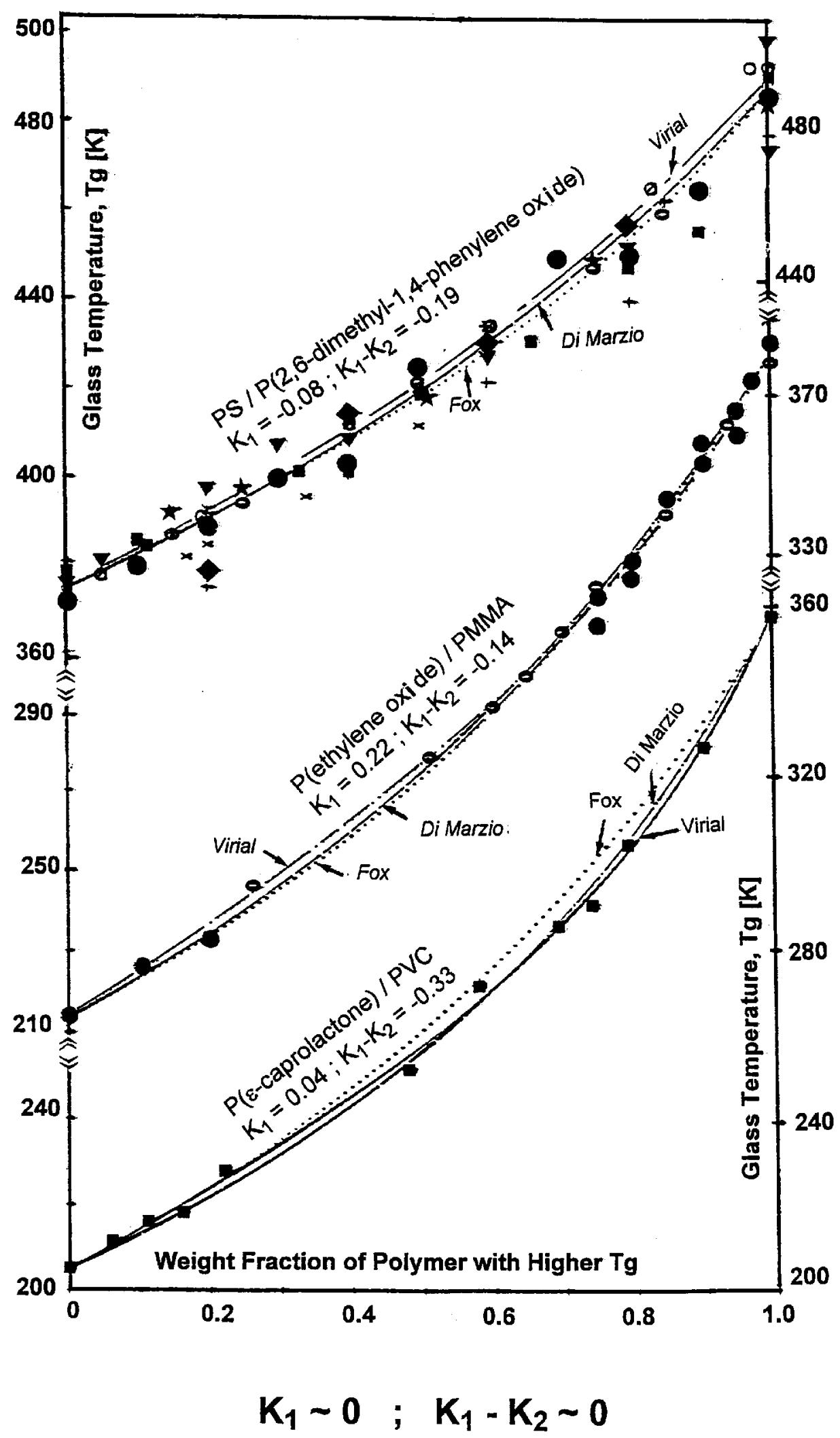

Fig. 5. $T_{\mathrm{g}}$ vs composition curves for polymer blends with almost additive $T_{\mathrm{g}}$. 


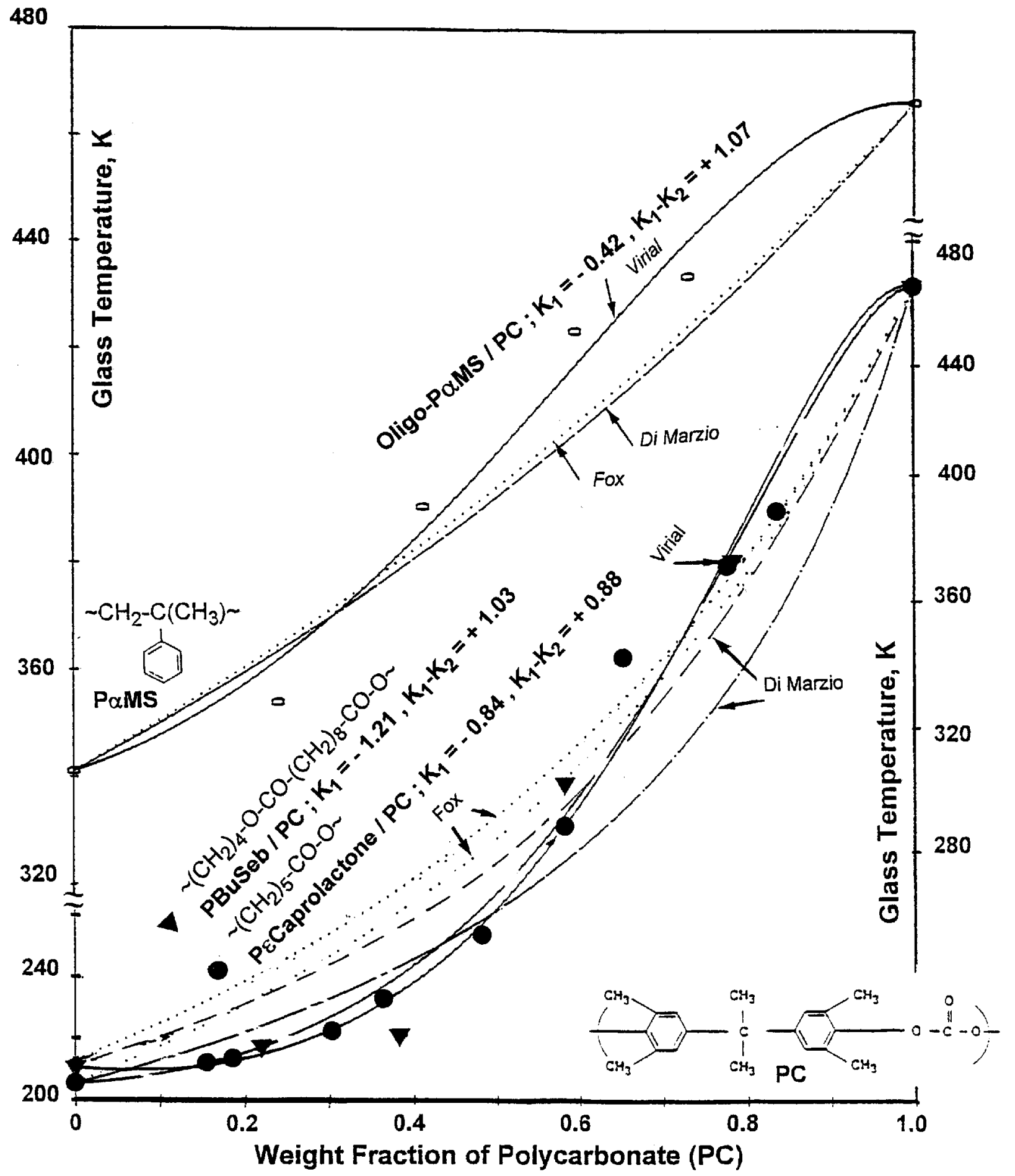

$\mathrm{K}_{1}<0 ; \mathrm{K}_{1}-\mathrm{K}_{2}>0$

Fig. 6. S-shaped $T_{\mathrm{g}}$ vs composition curves for polymer blends characterized by the parameters of the concentration power equation $K_{1}<0$ and $\left(K_{1}-K_{2}\right)>0$. 


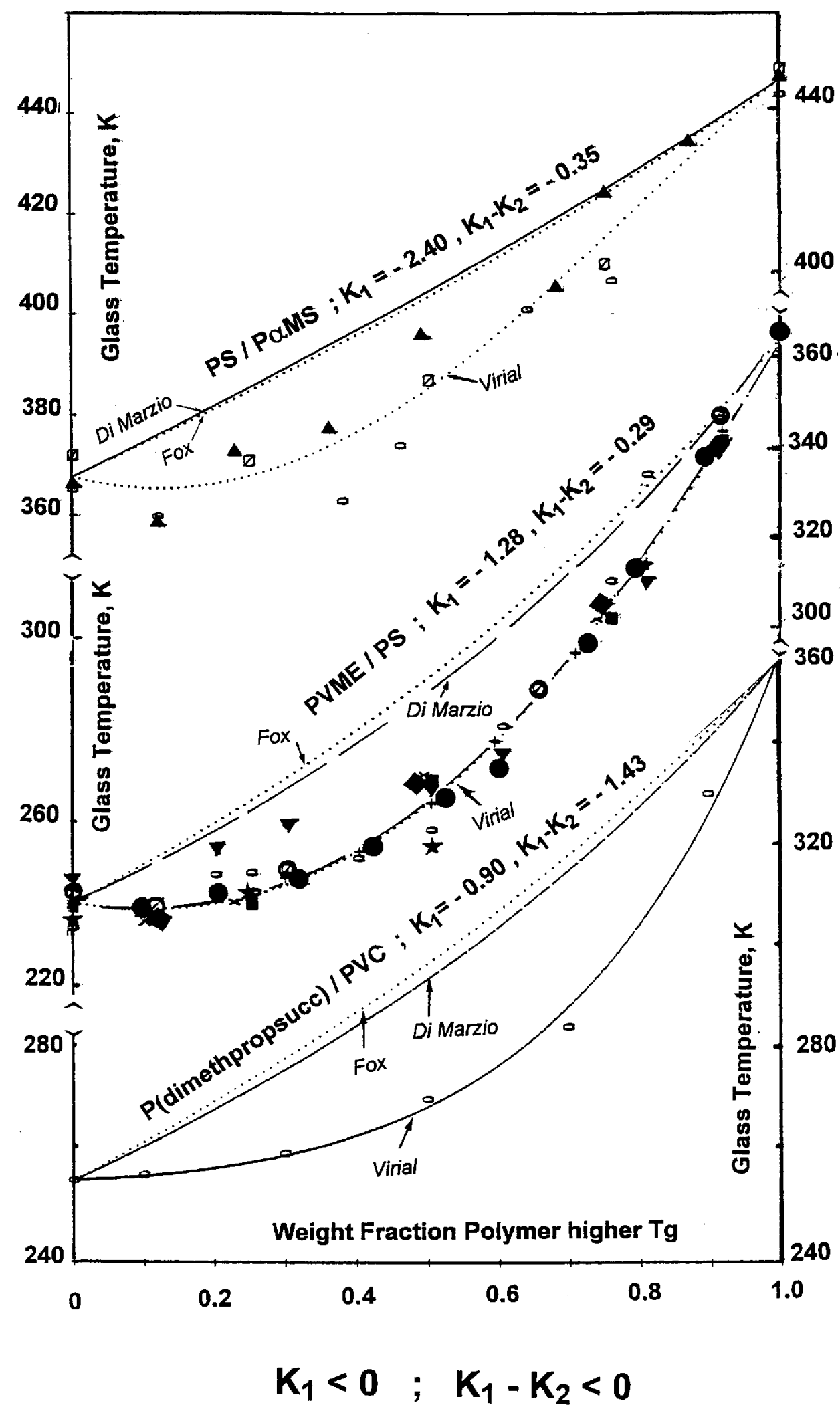

Fig. 7. $T_{\mathrm{g}}$ vs composition curves for polymer blends with negative deviations of the $T_{\mathrm{g}}$. 

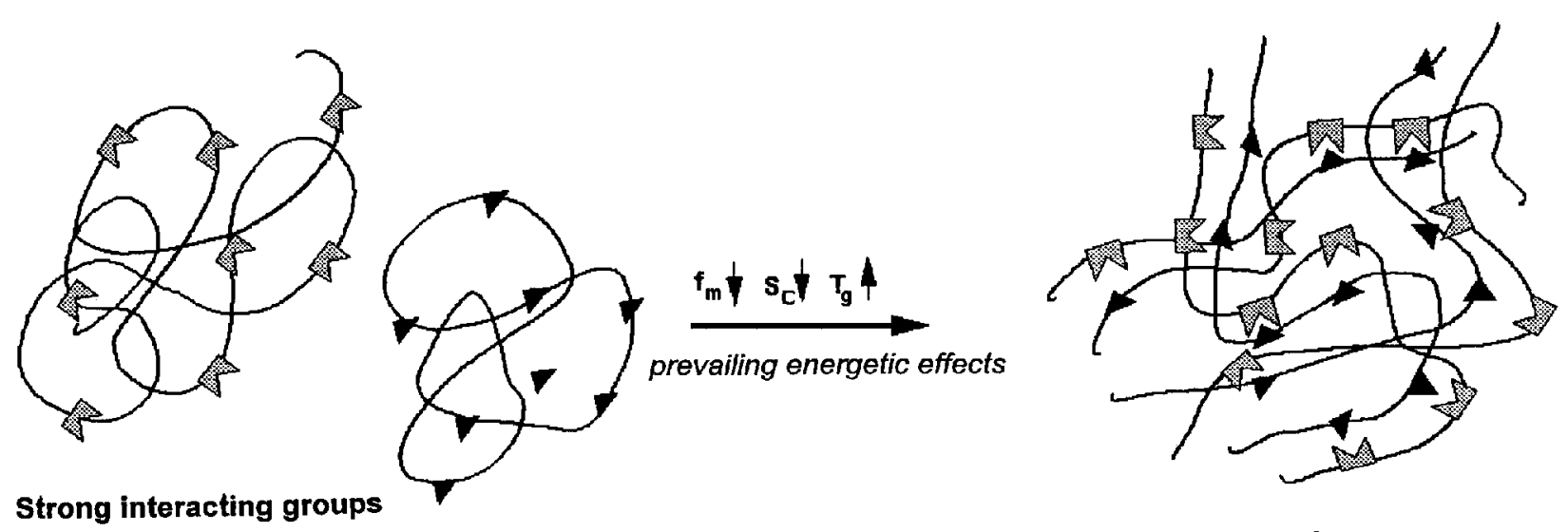

Strong interacting groups

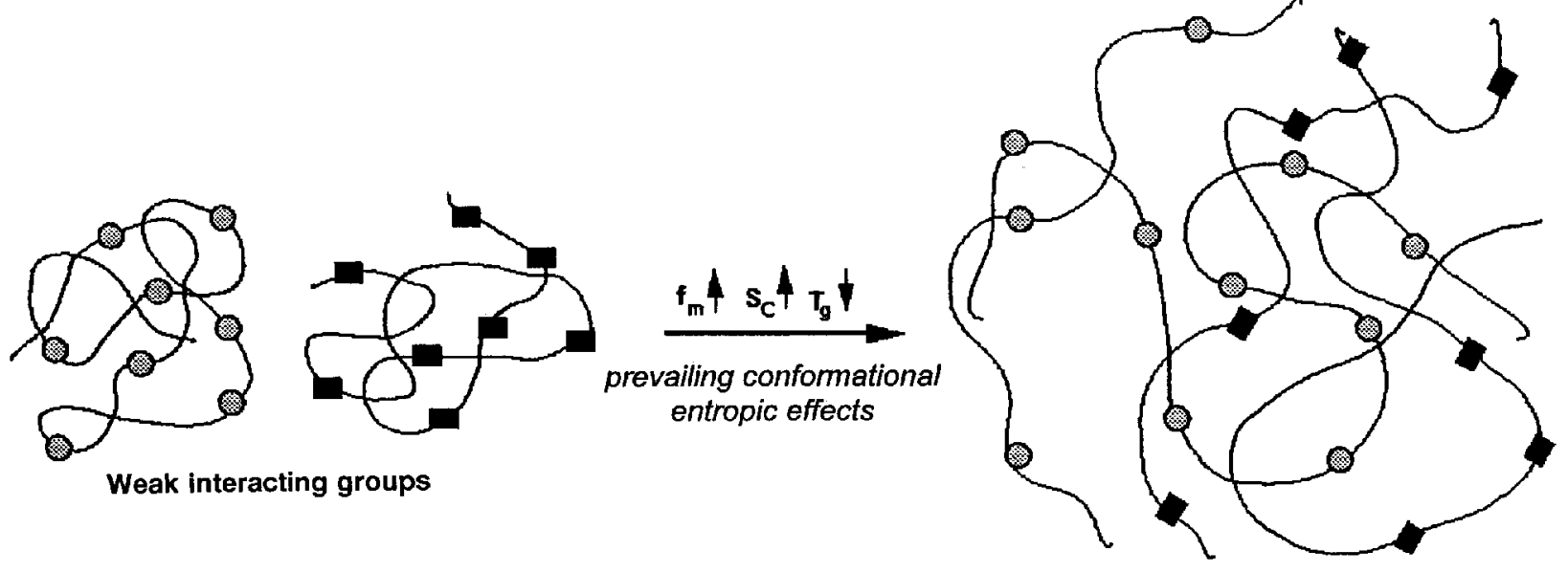

Fig. 8. Models for polymer blends with prevailing energetic local ordering effects or predominant conformational entropy contributions to the interaction energy of binary hetero-contacts.

the solubility parameters of the blend components, $\left(\delta_{2}-\right.$ $\left.\delta_{1}\right)$. The solubility parameters were estimated according to the group contribution method by using the sets of group constants recommended by Small based on van Krevelen's analysis [40].

Although the $K_{1}$ parameter, Eq. (10), comprises not only energetic contributions to miscibility, but also contains conformational entropic effects to the binary hetero-contact interaction energy, the correlation with the difference between the solubility parameters of the blend components is surprisingly good as is seen in the data presented in Fig. 10. Predominant energetic interaction effects, characterized by positive values of $K_{1}$ are connected with negative values of the difference of the solubility parameters. For preponderant conformational entropic contributions, indicated by negative values of $K_{1}$, on the contrary, positive values of the difference between the solubility parameters are specific. For additivity, both $K_{1}$ and the difference between the solubility parameters show values near zero.
Similar dependences are observed for the correlation between the differences of the $\left(K_{1}-K_{2}\right)$ parameters and of the solubility parameters, as shown in Fig. 11. The scatter of the data is, however, larger for the $\left(K_{1}-K_{2}\right)$ parameter difference. It is supposed that this different behavior is related to the asymmetry of the two expressions, Eqs. (10) and (12), respectively, which comprise beside the energetic contribution to miscibility, different shares of the conformational entropy effects on the binary hetero-contact interaction energies. The difference is evident mainly for the $\mathrm{S}$-shaped $T_{\mathrm{g}}$ vs composition curves, and is related with the fact that for S-shaped curves the absolute values of the parameter $K_{2}$ are larger then those of the $K_{1}$ parameter, causing an inversion of the sign for the $\left(K_{1}-K_{2}\right)$ difference, as is evidenced by the data shown in Fig. 12. 


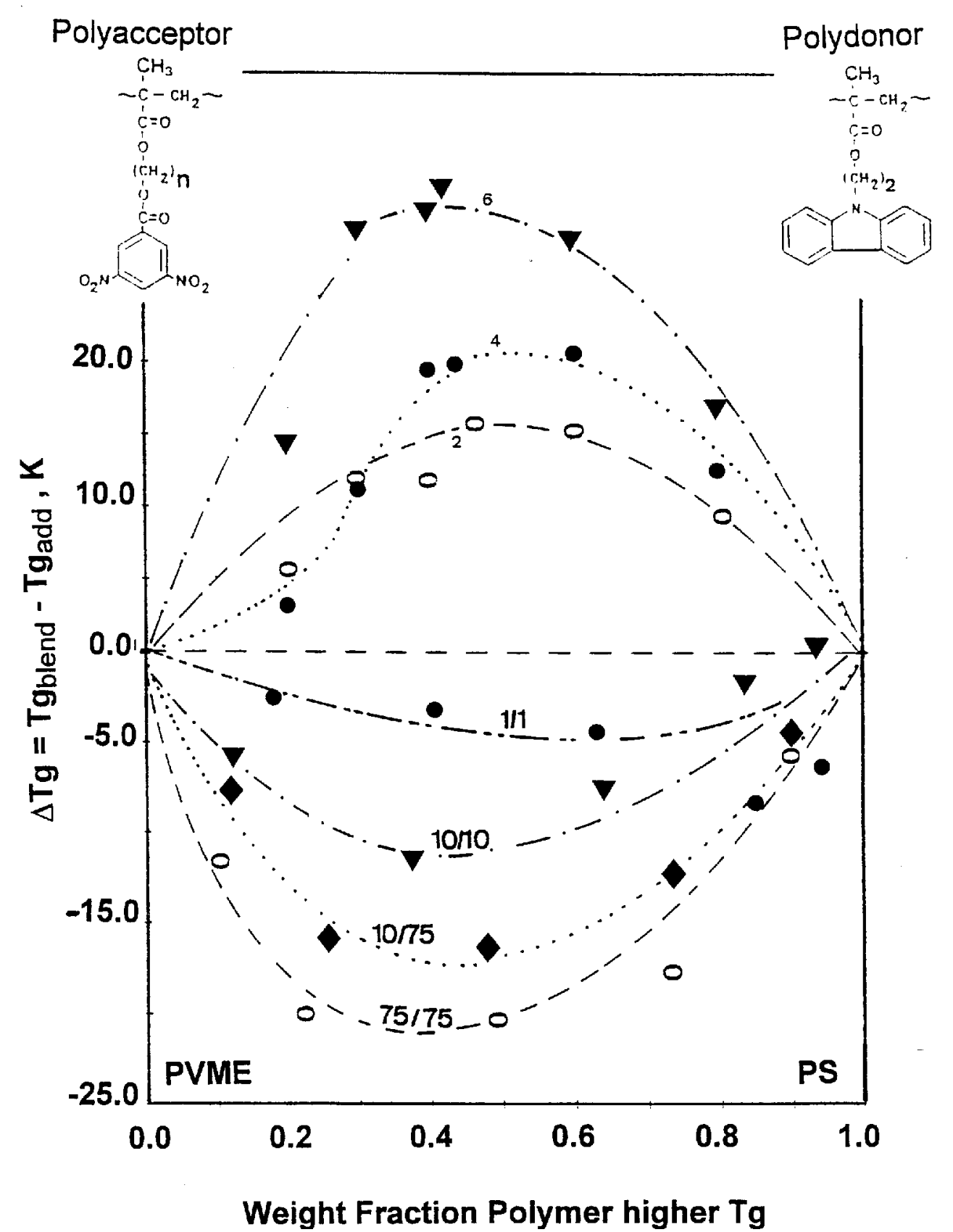

Fig. 9. Dependence of the deviation of the blend $T_{\mathrm{g}}$ from additivity—for the strong interacting polyacceptor/polydonor blends of PDNBM/PHECM on the spacer length between the acceptor group and methacrylic backbone of PDNBM; the figures on the curves indicate the number of methylenic units in the spacer of PDNBM-for the weaker interacting PVME/PS blends on the molecular weight of the blend components; the figures on the curves indicate the molecular weights in thousands of the components of the PVME/PS blends. 


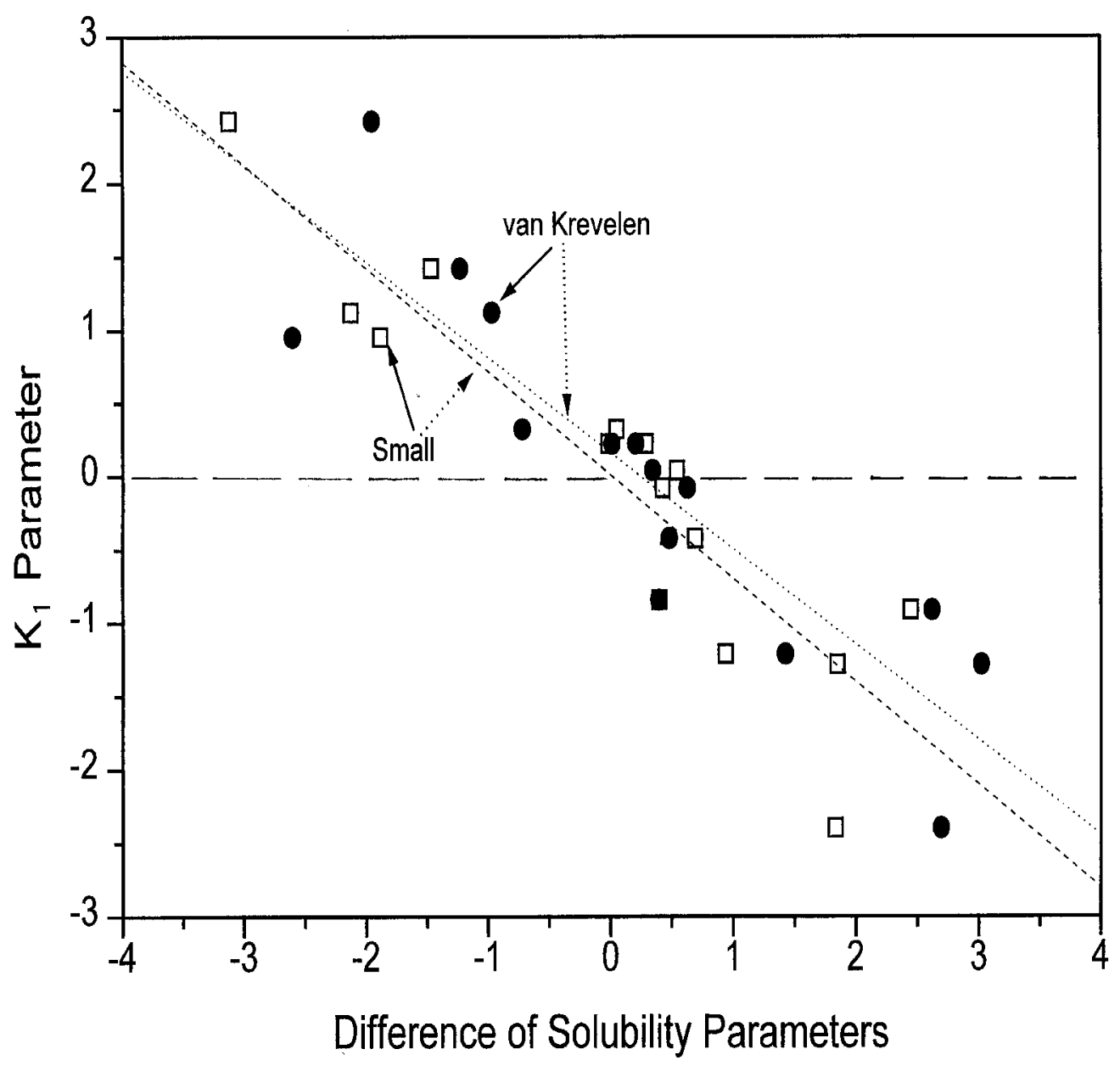

Fig. 10. Correlation between the $K_{1}$ parameter of the concentration power equation and the difference $\left(\delta_{2}-\delta_{1}\right)$ of the solubility parameters of the blend components. 


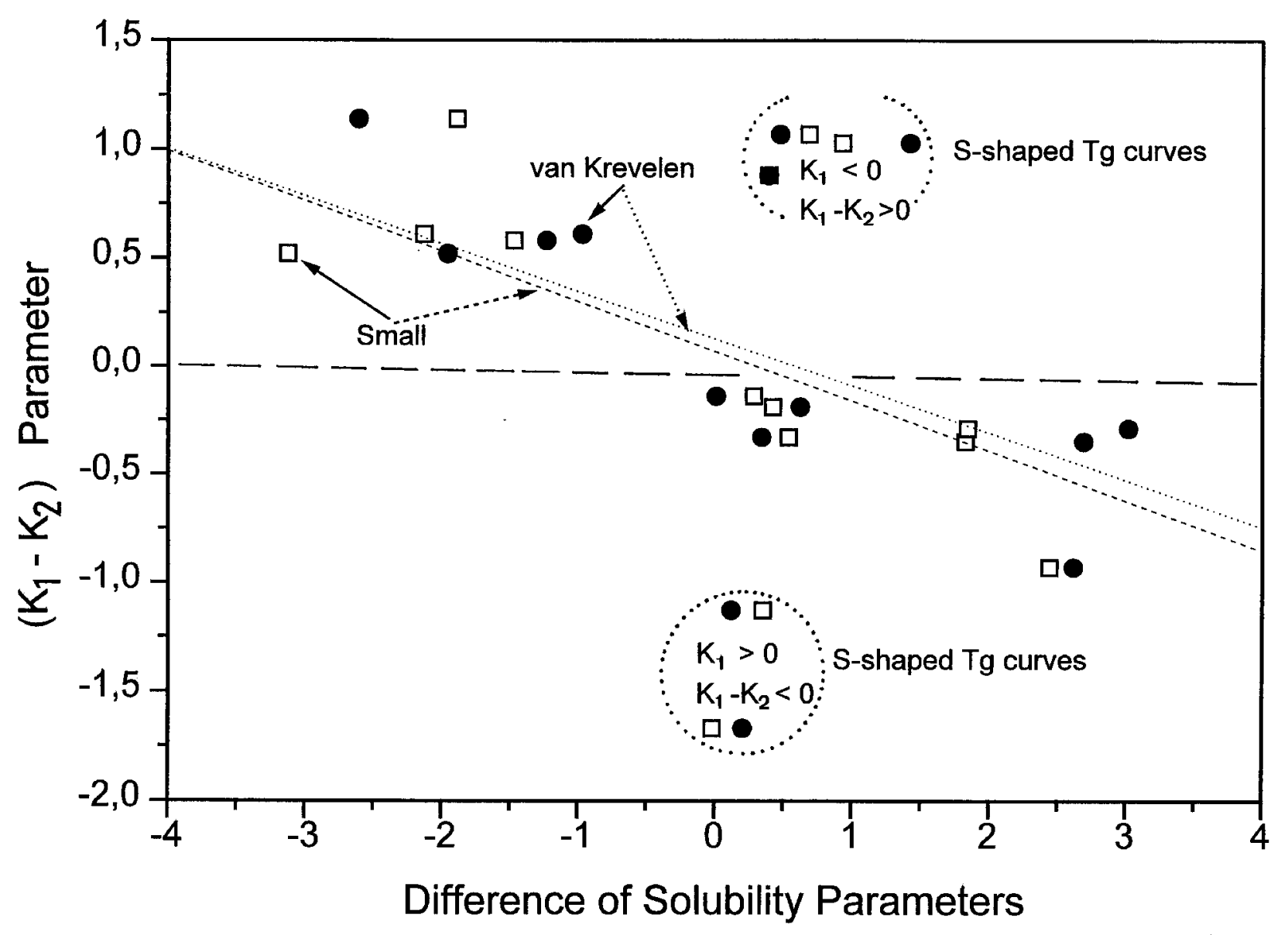

Fig. 11. Correlation between the difference $\left(K_{1}-K_{2}\right)$ of the concentration power equation and the difference $\left(\delta_{2}-\delta_{1}\right)$ of the solubility parameters of the blend components. 


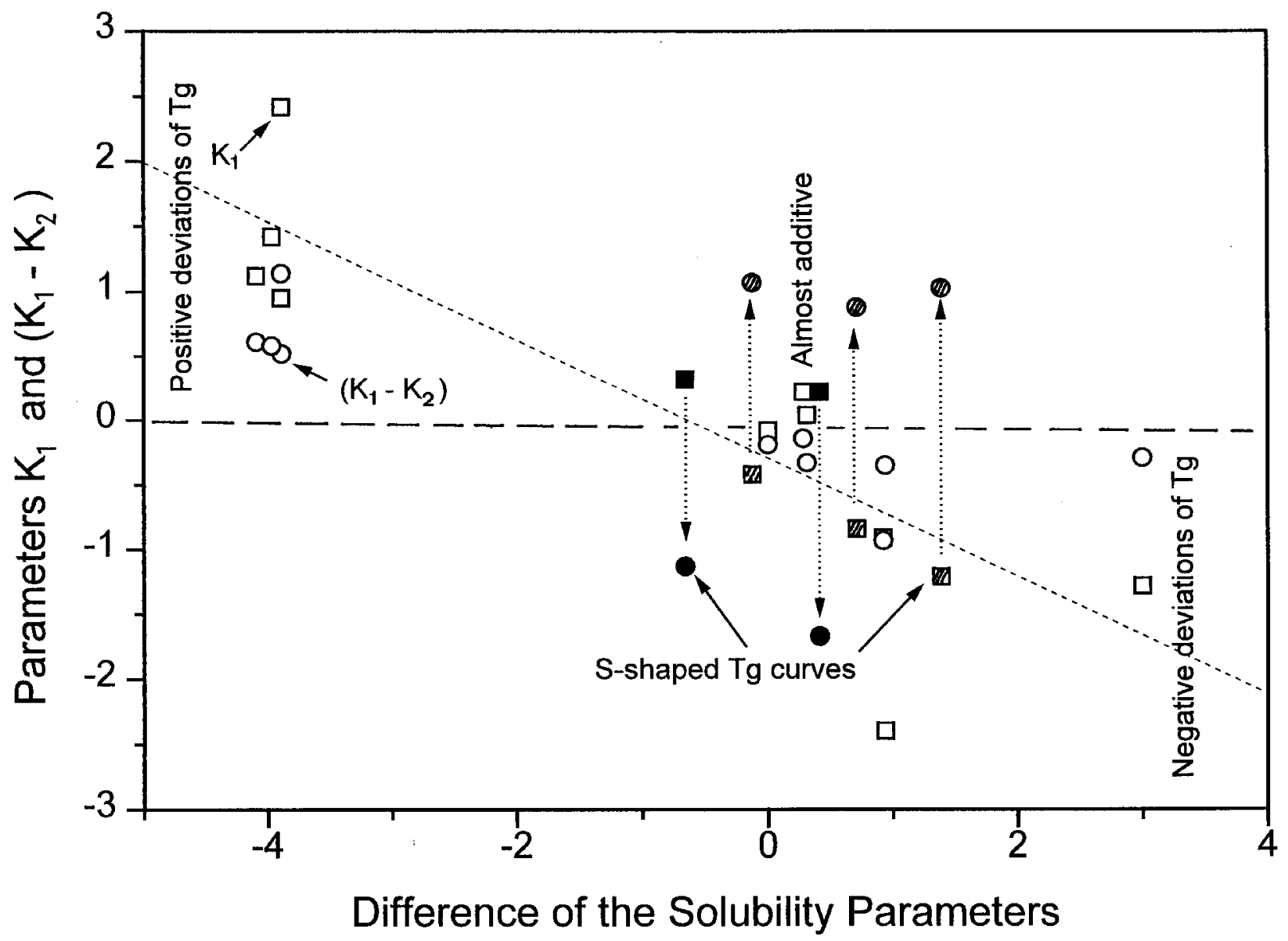

Fig. 12. Parameters of the concentration power equation vs difference of the solubility parameters of compatible polymer blends.

\section{Acknowledgments}

The author is obliged to Drs. Cantow, DiMarzio, and Simha for helpful suggestions. Financial support from the Deutsche Forschungsgemeinschaft (SFB 60) is gratefully acknowledged.

\section{References}

[1] W. Kauzmann, The nature of the glassy state and the behavior of liquids at low temperatures, Chem. Rev. 43, 219-256 (1948).

[2] G. Rehage, Thermodynamics of the glassy state of polymers, J. Macromol. Sci. Phys. B18, 423-443 (1980).

[3] A. K. Doolitle, Studies in newtonian flow. II. The dependence of the viscosity of liquids on free space, J. Appl. Phys. 22, 1471-1475 (1951); N. Hirai and H. Eyring, Bulk viscosity of polymeric systems, J. Polymer Sci. 37, 51-70 (1959); M. H. Cohen and D. Turnbull, Free-volume model of the amorphous phase: Glass Transition, J. Chem. Phys. 34, 120-125 (1961); R. Simha and T. Smocynsky, On the statistical thermodynamics of spherical and chain molecule fluids, Macromolecules 4, 342350 (1969); R. Simha, Configurational thermodynamics of the liquid and glassy polymeric states, Macromolecules 10, 10251030 (1977).

[4] J. H. Gibbs and E. A. DiMarzio, Nature of the glass transition and the glassy state, J. Chem. Phys. 28, 373-383 (1958); Chain stiffness and the lattice theory of polymer phases, J. Chem. Phys. 28, 807-813 (1958); E. A. DiMarzio, Equilibrium theory of glasses, Annals NY Acad. Sci. 37, 1-21 (1981).

[5] M. Gordon and J. S. Taylor, Ideal copolymers and the secondorder transitions of synthetic rubbers I. Non-crystalline copolymers, J. Appl. Chem., USSR 2, 493-500 (1952).

[6] A. J. Kovacs, Transition vitreuse dans les polyméres amorphes. Etude phénoménologique, Fortschr. Hochpolym. Forsch. 3, 394-507 (1963).

[7] E. A. DiMarzio and J. H. Gibbs, Glass temperature of copolymers, J. Polymer Sci. 40, 121-131 (1959); E. A. DiMarzio, The glass temperature of polymer blends, Polymer 31, 2294-2298 (1990).

[8] R. F. Boyer, $\Delta C_{p} T_{\mathrm{g}}$ and related quantities for high polymers, J. Macromol. Sci. Phys. B7, 487-501 (1973).

[9] P. R. Couchman and F. R. Karasz, A classical thermodynamic discussion of the effect of composition on glass-transition temperatures, Macromolecules 11, 117-119 (1978); P. R. Couchman, Compositional variation of glass-transition temperatures. 2. Application of the thermodynamic theory to compatible polymer blends, Macromolecules 11, 1157-1161 (1978). 
[10] R. Simha and R. F. Boyer, On a general relation involving the glass temperature and the coefficients of expansion of polymers, J. Chem. Phys. 37, 1003-1007 (1962).

[11] T. G. Fox, Influence of diluent and copolymer composition on the glass temperature of copolymers, Bull. Am. Phys. Soc. 1, (Session J.) 123 (1965).

[12] H. A. Schneider and E. A. DiMarzio, The glass temperature of polymer blends: comparison of both the free volume and the entropy predicitions with data, Polymer 33, 3453-3461 (1992).

[13] H. A. Schneider, The Gordon-Taylor Equation: Additivity and interaction in compatible polymer blends, Makromol. Chem. 189, 1941-1955 (1988).

[14] A. J. Hopfinger, M. G. Koehler, and R. A. Pearlstein, Molecular modeling of polymers. IV. Estimation of glass transition temperatures, J. Polymer Sci., Part B. Polymer Phys. 26, 2007-2028 (1988).

[15] P. Peyser, Glass transition temperatures of polymers, in Polymer Handbook, J. Brandrup and E. H. Immergut, eds., John Wiley \& Sons, New York, Third Ed. (1989), p.VI 209-VI 277.

[16] H. A. Schneider, N. Steinhauser, and R. Mülhaupt, Influence of flexible oligo-(tetraflouroethene) segments on the glass temperature of poly(aramide)s and poly(amide imide)s, Polymer Bull. 32, 339-346 (1994).

[17] H. A. Schneider, F. Glatz, and R. Mülhaupt, The influence of structural parameters on the glass temperature and compatibility of poly(phenylene ether ketone)s, New Poly. Mater. 4, 289-299 (1995).

[18] M. Bolsinger and H. A. Schneider, Influence of spacer length between interacting group and polymer backbone on the glass transition temperature of electron-donor/electron-acceptor blends, Macromol. Chem. Phys. 195, 2683-2692 (1994).

[19] E. Jenckel and R. Heusch, Die Erniedrigung der Einfriertemperatur organischer Gläser durch Lösungsmittel, Kolloid Z. 130, 89-105 (1953).

[20] T. K. Kwei, The effect of hydrogen bonding on the glass transition temperatures of polymer mixtures, J. Polymer Sci., Polymer Lett. Ed. 22, 307-313 (1984).

[21] G. Kanig, Zur Theorie der Glastemperaturen von Polymerhomologen, Copolymeren und weichgemachten Polymeren, Kolloid Z. Z. Polymere 190, 1-10 (1963).

[22] M.-J. Brekner, H. A. Schneider, and H.-J. Cantow, Approach to the composition dependence of the glass transition temperature of compatible polymer blends, Polymer 78, 78-85 (1988).

[23] M.-J. Brekner, H. A. Schneider, and H.-J. Cantow, Approach to the composition dependence of the glass transition temperature of compatible polymer blends. 2. The effect of local chain orientation., Makromol. Chem. 189, 2085-2097 (1988).

[24] J. M. Rodriguez-Parada and V. Percec, Interchain EDA complexes of poly[N-(2-hydroxyethyl)carbazolyl methacrylate] with poly( $\omega$-hydroxyalkyl-3,5-dinitro-benzoyl methacrylates), Polymer Bull. 14, 165-171 (1985); Interchain electron-donoracceptor complexes: A model to study polymer-polymer miscibility, Macromolecules 19, 55-64 (1986); V. Precec, H. G. Schild, J. M. Rodriguez-Parada, and C. Pugh, Interchain electron-donor-acceptor complexes. Determination of equilibrium constants and thermodynamic parameters in the solid state, J. Polymer Sci., Part A: Polymer Chem. 26, 935-951 (1988).

[25] U. Epple and H. A. Schneider, Glass transition behaviour of acrylic donor or acceptor copolymers. Homopolymers and their polymer blends, Thermochim. Acta 160, 103-112 (1990).

[26] T. Nishi and T. T. Wang, Melting point depression and kinetic effects of cooling on crystallization in poly(vinylidene flouride)poly(methylmethacrylate) mixtures, Macromol. 8, 909-915 (1975).
[27] L. Leung, P. J. Williams, F. E. Karasz, and W. J. Knight, Miscible blends of aromatic polybenzimidazoles and aromatic polyimides, Polymer Bull. 16, 457-464 (1986).

[28] A. C. Fernandes, J. W. Barlow, and D. R. Paul, Aliphatic polyester miscibility with polyepichlorohydrin, J. Appl. Polymer Sci. 29, 1971-1983 (1984).

[29] A. C. Fernandes, J. W. Barlow, and D. R. Paul, Blends containing tetramethyl bis-phenol-A polycarbonate. 1. Styrenic polymers, Polymer 27, 1788-1798 (1986).

[30] W. Guo and J. S. Higgins, Miscibility and kinetics of phase separation in polymer blends of tetramethyl-bis-phenol-A polycarbonate and polystyrene, Polymer 31, 699-706 (1990).

[31] X. Li and S. L. Hsu, An analysis of the crystallization behaviour of poly(ethylene oxide)/poly(methylmethacrylate) blends by spectroscopy and calorimetric techniques, J. Polymer Sci., Polymer Phys. Ed. 22, 1331-1342 (1984); K. E. Min, J. S. Chiou, J. W. Barlow, and D. R. Paul, A completely miscible ternary blend: poly(methyl methacrylate)-poly(epichlorohydrin)-poly(ethylene oxide), Polymer 28, 1721-1728 (1987); K. Assmann and $\mathrm{H}$. A. Schneider, The thermal analysis of blends of poly(ethylene oxide)/poly(methyl methacrylate), J. Thermal. Anal. 35, 459-468 (1989).

[32] J. J. Ziska, J. W. Barlow, and D. R. Paul, Miscibility in PVCpolyester blends, Polymer 22, 918-923 (1981).

[33] W. N. Prest Jr. and R. S. Porter, Rheological properties of poly(2,6-dimethyl-phenylene oxide) - polystyrene blends, J. Polymer Sci., Part A-2 10, 1639-1655 (1972); A. R. Shultz and B. M. Gendron, Thermo-optical and DSC observations of mobility transitions in polystyrene - poly(2,6-dimethyl-1,4phenylene oxide) blends, J. Appl. Polymer Sci. 16, 461-471 (1972); T. K. Kwei and H. L. Frisch, Interaction parameters in polymer mixtures, Macromolecules 11, 1267-1271 (1978); S. P. Ting, E. M. Pearce, and T. K. Kwei, Compatibility studies of poly(styrene-covinylphenylhexanflourodimethylcarbinol) with bisphenol-A polycarbonate, poly-(methyl methacrylate) and poly(2,6-dimethyl-1,4-phenylene oxide), J. Polymer Sci., Polymer Lett. Edn. 18, 201-209 (1980); M. A. de Araujo, R. Stadler, and H. J. Cantow, Composition and molecular-weight dependence of the glass transition in polystyrene - poly(2,6dimethylphenylene oxide) blends, Polymer 29, 2235-2243 (1988); H. Gräter, Ph.D. Thesis, University Freiburg, 1987.

[34] A. C. Fernandes, J. W. Barlow, and D. R. Paul, Blends containing tetramethyl bisphenol-A polycarbonate, Polymer 27, 17991806 (1986).

[35] G. L. Brode and J. V. Koleske, Lactone polymerization and polymer properties, J. Macromol. Sci., Chem. A-6, 1109-1144 (1972).

[36] J. E. Harris, S. H. Goh, D. R. Paul, and J. W. Barlow, Miscible binary blends containing polyhydroxyether of bisphenol-A and various aliphatic polyester, J. Appl. Polymer Sci. 27, 839-855 (1982).

[37] M. Bank, J. Leffingwell, and C. Thiess, The influence of solvent on the compatibility of polystyrene and poly(vinyl methyl ether), Macromolecules 4, $43-46$ (1971); T. K. Kwei, T. Nishi, and R. F. Roberts, A study of compatible polymer mixtures, Macromolecules 7, 667-674 (1974); J. L. Halary, F. C. Ben Larbi, P. Oudin, and L. Monnerie, Molecular mobility in polystyrene-poly(methylvinyl ether) blends, Makromol.Chem. 189, 2117-2124 (1988).

[38] H. A. Schneider and M.-J. Brekner, Thermodynamic aspects of the glass transition in the compatible blend poly(styrene)poly(vinylmethylether), Polymer Bull. 14, 173-178 (1985); H. A. Schneider and B. Leikauf, Glass transition temperatures of PVME-PS blends. Influence of the molecular weight of PS, Thermochim. Acta 114, 165-170 (1987); B. Leikauf, Ph.D. Thesis, University Freiburg, 1986. 
[39] Suk-fai Lou, J. Pathak, and B. Wunderlich, Study of phase separation in blends of polystyrene and poly $(\alpha$-methylstyrene) in the glass transition region using quantitative thermal analysis, Macromolecules 15, 55-64 (198?); S. Saeki, J. M. G. Cowie, and I. J. Mc Ewen, The effect of molecular weight and casting solvent on the miscibility of polystyrene - poly $(\alpha$-methylstyrene) blends, Polymer 24, 60-64 (1983); J.-L. Lin and R.-J. Roe, DSC study of miscibility of polystyrene and $\operatorname{poly}(\alpha-$ methylstyrene), Polymer 29, 1227-1234 (1988); H. A. Schneider and P. Dilger, DSC and TMS study of polystyrene poly $(\alpha$-methylstyrene) blends, Polymer Bull. 21, 265-272 (1989).

[40] E. A. Grulke, Solubility Parameter Values, in J. E. Brandrup and E. H. Immergut, eds., Polymer Handbook, IIIth Ed., John Wiley \& Sons, New York (1989) pp. VII/519-VII/559.

About the author: Hans Adam Schneider is a professor at the Institute of Polymer Chemistry (Institut für Makromolekulare Chemie) and a member of the Materials Research Center (Freiburger Materialforschungszentrum, FMF) of the University of Freiburg, Germany. 